\title{
Synergistic Effect of 4A Zeolite from Rice Husk Ash without Aging Time and Silane on the Adhesion Properties of a Warm Mix Asphalt
}

\author{
Paula C. Arroyo-Martínez, ${ }^{a}$ Norma A. Sánchez-Flores, ${ }^{* a}$ María E. Villafuerte-Castrejón ${ }^{b}$ \\ and Rodrigo Vivar-Ocampo ${ }^{b}$ \\ ${ }^{a}$ Centro de Ciencias Aplicadas y Desarrollo Tecnológico and \\ ${ }^{b}$ Instituto de Investigaciones en Materiales, Universidad Nacional Autónoma de México, \\ Circuito exterior s/n, Ciudad Universitaria, Coyoacán, CP 04510, Ciudad de México, México
}

\begin{abstract}
4A Zeolite was synthesized using rice husk ash (RHA) as a raw material in a microwaveassisted hydrothermal synthesis. Two new procedures were proposed: procedure A, using RHA as the raw material, and procedure B, using the depolymerized RHA. Both procedures were performed using microwave-assisted hydrothermal synthesis, and neither synthesis required an aging time. Crystallinities of over 90 and $80 \%$ were reached at $100{ }^{\circ} \mathrm{C}$ after $30 \mathrm{~min}$ of microwave heating for procedures A and B, respectively. The obtained zeolites were used as warm mix asphalt additives, and the performance of the zeolite obtained from procedure A was better. Additionally, the zeolite obtained from procedure A and commercial silane were used separately as asphaltaggregate adhesion promoter. An increase in the adhesion percentage from $30 \%$ of a blank sample to $94 \%$ was observed.
\end{abstract}

Keywords: 4A zeolite, rice husk ash, microwave-assisted synthesis, aging time, warm mix asphalt additives

\section{Introduction}

Warm mix asphalts consist of asphalt mixtures heated at temperatures from 20 to $50{ }^{\circ} \mathrm{C}$, cooler than those in which hot mix asphalts are heated. ${ }^{1}$ The widespread use of warm mix asphalts has been promptly accepted due to some advantages, such as reduced emissions, better working conditions because of the absence of harmful gases, lower energy consumption in mix production, quicker turnover to traffic, longer hauling distances and an extended paving window. ${ }^{2}$ Recently, the use of synthetic zeolites as warm mix asphalt additives has been published. ${ }^{1-11}$

Due to the size and uniformity of their pores, ${ }^{7,12,13} 4 \mathrm{~A}$ zeolites are water carriers that are able to release water between 12 and $18 \%$ in weight when mixed with the asphalt, ${ }^{14}$ preferably at a temperature greater than $100{ }^{\circ} \mathrm{C} .{ }^{1,4}$ A foaming effect is produced, this facilitates the asphalt workability and increases the aggregate coating at a warm mix asphalt temperature. ${ }^{15}$ The use of zeolites as warm mix asphalt additives has exhibited numerous additional advantages, such as a reduced susceptibility to permanent deformation. . $^{5,15-18}$

*e-mail: norma.sanchez@ccadet.unam.mx
However, there are also indications that the use of zeolites as warm mix asphalt additives increases the moisture sensitivity of pavements; $;^{5,7,10,13}$ therefore, the use of an antistripping additive has been suggested to counteract that effect. ${ }^{5,7,13,19,20}$ Some silanes, such as trimethoxy(octyl)silane and [3-(2-aminoethylamino) propyl] trimethoxysilane, show good antistripping performance ${ }^{21,23}$ and have been proven to increase the adhesion between the asphalt and the aggregate. ${ }^{24}$

There are numerous types of zeolites. Zeolites have been the subject of numerous studies in many fields of research because of their properties and characteristics, ranging from synthesis to applications, and there is still much to be discovered about their properties. According to Sherman, ${ }^{25}$ in the late 1940s, Milton synthesized different zeolites by applying hydrothermal crystallization to reactive alkali metal aluminosilicate gels at low temperatures and pressures.

One of the most significant commercially demanded families of zeolites are the Linde Type A (LTA), including the 3A, 4A and 5A zeolites, due to their characteristics, such as a high ion exchange capacity, sorption and catalytic activities, and their large-scale industrial application, ${ }^{26}$ in addition to the relatively easy ways in which they can be obtained at low temperatures and pressures. ${ }^{25}$ The 
synthesis of LTA zeolite requires both a source of silica and a source of alumina. These are mixed and placed under crystallization conditions, which usually implies an alkaline solution. The most commonly used and reported sources of silica are sodium silicate ${ }^{27,28}$ and silatrane; $;^{29,30}$ however, some authors have reported the use of industrial waste as a source of silica to obtain a silicate solution, such as coal fly ash $^{31}$ and rice husk ash (RHA) ${ }^{32-34}$ The crystallization conditions, mixing conditions and sources of reactants vary from method to method.

RHA is considered an agricultural by-product that contains a substantial amount of amorphous silica (83-90\%); therefore, it has become an economically viable raw material for the production of value-added products..$^{35}$ There are numerous studies that synthesize LTA zeolites hydrothermally using RHA as a raw material; unfortunately, after obtaining the amorphous silica, the preparation of the silicate solution implies high temperatures and long periods of time. ${ }^{32,36-41}$ For example, the process has been reported using temperatures from over $70{ }^{\circ} \mathrm{C}$ to the boiling point, and periods range from $1 \mathrm{~h}$ to one week under shaking or stirring conditions. . $2,36,38,40,41$ Once this process is complete, a gel solution is prepared by mixing the silicate solution with sodium aluminate solution. This is followed by the application of crystallization conditions, the time and temperature vary from over 2 to $48 \mathrm{~h}$ at a temperature of approximately $100{ }^{\circ} \mathrm{C}^{32,33,36-42}$

Zeolite crystallization reactions can be caused by a conventional hydrothermal synthesis and through a microwave-assisted hydrothermal synthesis. ${ }^{43}$ The latter has been reported to offer advantages, such as decrease of the crystallization time,,$^{14,27,43-47}$ narrowing the particle size distribution and increase of the shape homogeneity. ${ }^{44,47}$ Although some authors attribute these outcomes to the thermal effect, ${ }^{43}$ others believe them to be the result of the so-called microwave non-thermal effect. ${ }^{46}$ Nevertheless, the effects of the microwave irradiation on the chemical reactions have not been fully understood and remain controversial. $^{46,48}$

The use of microwave-assisted hydrothermal synthesis to obtain LTA zeolite has been reported several times ${ }^{27,30,44,45,47,49-55}$ using different procedures and conditions. The synthesis is usually developed from a gel originated from a sodium aluminate and a sodium silicate solution requiring long and vigorous stirring to be homogenized. There is a previous step called aging time that has been frequently identified during the synthesis procedures. This period is reported to accelerate the crystallization, control the crystal size, suppress impurity faces $^{56}$ and avoid seeding in the membrane synthesis. ${ }^{45}$ Aging times vary from a few hours ${ }^{55}$ to several days ${ }^{47}$ with temperatures ranging from room temperature ${ }^{47,50}$ to $60{ }^{\circ} \mathrm{C}$. This step is related to the number of formed nuclei and the so-called product-promoting effect ${ }^{57}$ and has been used to substitute seeding. ${ }^{45}$ Finally, depending on the gel characteristics, microwave heating is applied to achieve temperatures of approximately $100{ }^{\circ} \mathrm{C}$ in periods that vary from minutes to even hours.

Hence, the goal of this work is to present a novel method of synthesizing $4 \mathrm{~A}$ zeolite directly from a residual waste (rice husk ash) in a short time using microwave assistance. In addition, 4A zeolite has been tested in asphalt mixtures showing the effect that the synthesized zeolite exerts on the antistripping additive (silane compound) at warm mix asphalt temperatures.

\section{Experimental}

\section{Reagents}

Rice husk (RH) was donated by Arrocera San José, Morelos, Mexico. Sodium aluminate (purity $>99 \%$, ICN, Biomedicals Inc.), anhydrous glycerol (purity $>99.5 \%$, JT Baker), sodium hydroxide (purity $\geq 97 \%$, Sigma-Aldrich), toluene (purity $>99.5 \%$, Sigma-Aldrich), deionized water, [3-(2-aminoethylamino) propyl] trimethoxysilane (purity $>99 \%$, UItra-Chem), asphalt binder (Ekbe Superpave PG-64-22, Salamanca, Mexico, donated by Súrfax S. A. de C. V.), and aggregate (granite from northern Mexico, donated by Súrfax S. A. de C. V.) were used.

\section{Synthesis of $4 \mathrm{~A}$ zeolite}

RH was calcined in a muffle furnace at $500{ }^{\circ} \mathrm{C}$ over a $24 \mathrm{~h}$ period. Then, the obtained RHA was triturated in a porcelain mortar. RHA was used as a source of silica in the raw state (procedure A). In parallel, RHA was also subjected to a depolymerization process in anhydrous glycerol as previously reported in the synthesis of ZSM-5 and silicalite- $1,{ }^{58,59}$ at $200{ }^{\circ} \mathrm{C}$ for $2 \mathrm{~h}$; the excess of glycerol was eliminated though decanting the obtained gel, and the remaining material was used as a source of silica (procedure B).

The following two solutions were prepared: the first from $1 \mathrm{~g}$ of the silica source, in $12 \mathrm{~mL}$ of a $2 \mathrm{~mol} \mathrm{~L}^{-1}$ $\mathrm{NaOH}$ solution, obtaining an RHA solution, and the second from $1.39 \mathrm{~g}$ of sodium aluminate as an aluminum source, dissolved in $12 \mathrm{~mL}$ of a $2 \mathrm{~mol} \mathrm{~L}^{-1} \mathrm{NaOH}$ solution. Both solutions were stirred for $15 \mathrm{~min}$. The RHA solution was then immediately added to the sodium aluminate solution and stirred for an additional $15 \mathrm{~min}$. Then, the resulting solution $(24 \mathrm{~mL})$ was placed in a MARS 6 CEM 
Corporation $600 \mathrm{~W}$ microwave for heating. The 4A zeolite was synthesized in the microwave oven in an airtight Teflon closed-vessel with controlled temperature and magnetic stirring. The oven was programmed to reach the set temperature of $100{ }^{\circ} \mathrm{C}$ in $15 \mathrm{~min}$. The temperature was maintained at $100{ }^{\circ} \mathrm{C}$ with microwave heating for periods of $0.5,1.0$, and $1.5 \mathrm{~h}$, producing samples 1,2 and 3 , respectively. The products were rinsed and centrifuged until the supernatant presented a $\mathrm{pH}$ value below 9. The samples were dried at $100{ }^{\circ} \mathrm{C}$ for $12 \mathrm{~h}$ and labeled A1, A2 and $\mathrm{A} 3$ or $\mathrm{B} 1, \mathrm{~B} 2$ and $\mathrm{B} 3$, according to the process from which they came and the microwave heating times to which they were subjected.

The obtained samples were characterized using X-ray diffraction (XRD), X-ray fluorescence (XRF), Fourier transform infrared spectroscopy (FTIR) and scanning electron microscopy (SEM).

\section{Application-adhesion test}

For this test, an asphalt mixture was used consisting of $50 \mathrm{~g}$ of granite aggregate with $5 \mathrm{~g}$ of asphalt binder and a certain amount of an asphalt additive (sample A1, commercial products) measured in weight percentage (wt.\%), proportional to the asphalt. The temperature range was kept between 110 and $130{ }^{\circ} \mathrm{C}$ (considered warm mix asphalt temperatures). The adhesion between the asphalt and aggregate was evaluated according to the Mexican Norm M-MMP 4.04.009/03. ${ }^{60}$

In the Mexican Norm, adhesion is measured as a stripping percentage (sp.\%) representing the amount of asphalt that is detached from the aggregate after being subjected to stress; therefore, the sp.\% of the reference samples lacking any adhesion promoter is frequently higher than that in those that contain an additive. Nevertheless, in this article, the results are presented as adhesion percentage (ap.\%).

The stress procedure described in Mexican Norm M-MMP 4.04.009/03 consists of placing an asphalt mixture, with individually separated asphalt-coated stones, and tap water in a glass bottle for $18 \mathrm{~h}$. The water is promptly changed, and a friction stress process is initiated by vertically rotating the bottle for $3 \mathrm{~h}$ at ca. $45 \mathrm{rpm}$. The asphalt-coated stones are drained, and the amount of adhered asphalt is visually calculated.

\section{Characterization techniques}

XRD analyses were recorded with a Bruker D-8 Advance AXS goniometer fitted with a secondary-beam graphite monochromator filtering the $\mathrm{Cu} K \alpha 1$ radiation ( $\lambda$ at $1.54186 \AA$ ). The wide-angle XRD was recorded between 2 and $60^{\circ}$ with a $2 \theta$ step of $0.02^{\circ}$ and a $1.2 \mathrm{~s}$ counting time per point. The crystallinity was calculated by integrating the crystalline area of the XRD patterns using Diffrac plus software from Bruker.

Thermogravimetric analysis (TGA) was carried out with a TA Instruments (TGA Q5000) under $\mathrm{N}_{2}$ gas flow and a constant heating rate of $10{ }^{\circ} \mathrm{C} \mathrm{min}^{-1}$ from room temperature $\left(25{ }^{\circ} \mathrm{C}\right)$ to $800{ }^{\circ} \mathrm{C}$.

$\mathrm{N}_{2}$ adsorption-desorption isotherms and specific surface area were measured with an automated gas sorption system (Micromeritics Flowsorb II-2300) after outgassing at $300{ }^{\circ} \mathrm{C}$ for $18 \mathrm{~h}$. The specific surface area was calculated in accordance with the method proposed by Brunauer, Emmett and Teller (BET).

FTIR spectra were recorded with a Nicolet 5SX FTIR spectrometer, fitted with CsI optics, at $4 \mathrm{~cm}^{-1}$ resolution and recording a total of 64 scans. The samples were prepared using the $\mathrm{KBr}$ self-supported pellet technique.

The chemical analysis by XRF was performed with a Rigaku ZSX Primus II spectrometer, fitted with a Rh anticathode and Be windows. The samples were prepared using metaborate and lithium tetraborate pearls, with geochemical references.

The microstructural characterization was performed using a Jeol JSM-7600F field emission scanning electron microscope (SEM) equipped with an Oxford INCA X-Act energy dispersive spectrometer. The samples were fixed on a double-sided carbon tape attached to a sample holder. The SEM elemental analysis was performed at an acceleration voltage of 20-25 kV and a pressure of 20-25 Pa.

\section{Results and Discussion}

\section{Reagents}

RHA (amorphous silica) was obtained after an RH calcination process at $500{ }^{\circ} \mathrm{C}$ for $24 \mathrm{~h}$. The chemical analysis performed with XRF shows a composition rich in silicon, at approximately $93 \mathrm{wt} \%$ in addition to several minor components (Table 1). According to the XRD analysis, the obtained pattern represents amorphous silica, distinguishable by a broad halo near $2 \theta$ at $23^{\circ}$ (not shown). From the low-temperature physical adsorption of $\mathrm{N}_{2}$, the measured BET specific surface area is $155 \mathrm{~m}^{2} \mathrm{~g}^{-1}$, characterized by a wide pore size distribution that indicates the mesoporous character of RHA (Figure 1).

\section{Synthesis of the $4 \mathrm{~A}$ zeolite}

From the two procedures described above (A and B), a crystalline component was obtained and identified by 
Table 1. Chemical analysis of rice husk ash (RHA) obtained through XRF

\begin{tabular}{lcccccccccc}
\hline $\mathrm{SiO}_{2} / \%$ & $\mathrm{TiO}_{2} / \%$ & $\mathrm{Al}_{2} \mathrm{O}_{3} / \%$ & $\mathrm{Fe}_{2} \mathrm{O}_{3} \mathrm{t} / \%$ & $\mathrm{MnO} / \%$ & $\mathrm{MgO} / \%$ & $\mathrm{CaO} / \%$ & $\mathrm{Na}_{2} \mathrm{O} / \%$ & $\mathrm{~K}_{2} \mathrm{O} / \%$ & $\mathrm{P}_{2} \mathrm{O}_{5} / \%$ & $\mathrm{LTC}^{\mathrm{a}} / \%$ \\
\hline 92.120 & 0.015 & 0.001 & 0.078 & 0.096 & 0.042 & 0.559 & 0.015 & 2.261 & 0.445 & 4.180 \\
\hline
\end{tabular}

a Loss through calcination of organic residues.

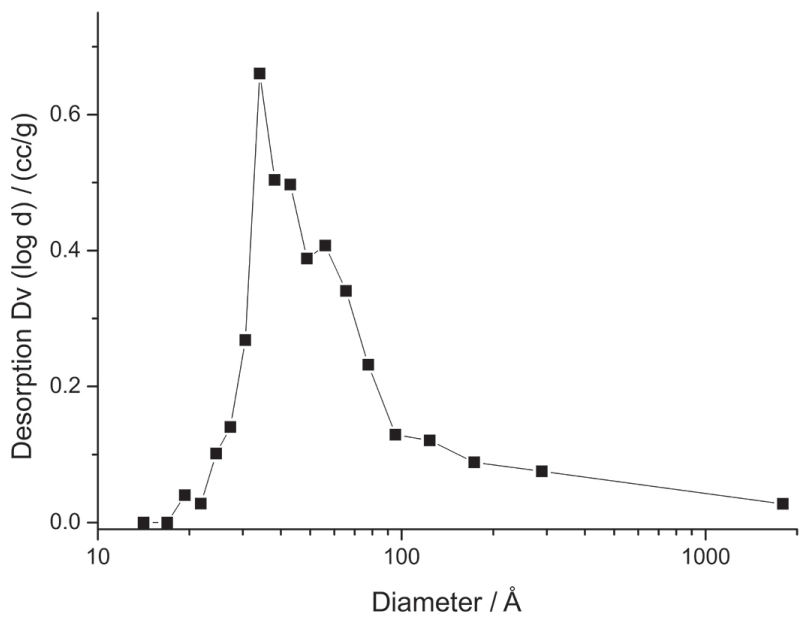

Figure 1. Pore size distribution of rice husk ash (RHA).

XRD analysis as a highly crystalline 4A zeolite (Figures 2a and $2 \mathrm{~b}){ }^{61}$ From these figures, it is clear that the degree of crystallinity is independent of the microwave-heating time. However, the degree of crystallinity is affected by the silica source. The crystallinity in the A samples was higher than that in the B samples (92 and 85\%, respectively) and the presence of sodalite impurities in A1 and B samples is evident. ${ }^{61}$ This is remarkable considering that even though up to $30 \mathrm{~min}$ of microwave heating time was used and the raw material was RHA, the precondition of an aging step for the formation of zeolite crystals was completely omitted.
However, the FTIR spectra illustrate the differences between the two procedures. For the A samples, it is possible to observe four frequency characteristics in the 4A zeolite spectra at approximately 990, 660, 560 and $460 \mathrm{~cm}^{-1}$ assigned to the asymmetric stretching vibration, symmetric stretching vibration, double ring vibration and pore opening vibration, respectively (Figure 3a). ${ }^{62}$ However, in the B samples, it is possible to observe the following two bands, likely due to the presence of residual glycerol: the first is a result of the deformation vibration belonging to primary $\mathrm{OH}\left(698 \mathrm{~cm}^{-1}\right)$ and the second is caused by the deformation vibration of $\mathrm{C}-\mathrm{O}$, shown by a clear widening of the band at $430 \mathrm{~cm}^{-1}$ (Figure 3b). ${ }^{63}$

The SEM micrographs of the synthesized samples show cubic crystal structures matching the most typical 4A zeolite shape (Figure 4). Only a few morphological differences between procedures A and B are observed. From procedure A, a cubic shape is observed with appreciable variation in the size distribution, while in procedure $\mathrm{B}$, the zeolites variation is lower. Procedure A displays a predominant size of approximately $3 \mu \mathrm{m}$, while in procedure $B$, this value is approximately $5 \mu \mathrm{m}$.

Morphological differences originated during the $4 \mathrm{~A}$ zeolite growth due to the differences between procedures $\mathrm{A}$ and $\mathrm{B}$. This variation is related to the use of RHA, depolymerized silica from RHA, and the depolymerization process itself. This process exposes and fragments the (a)

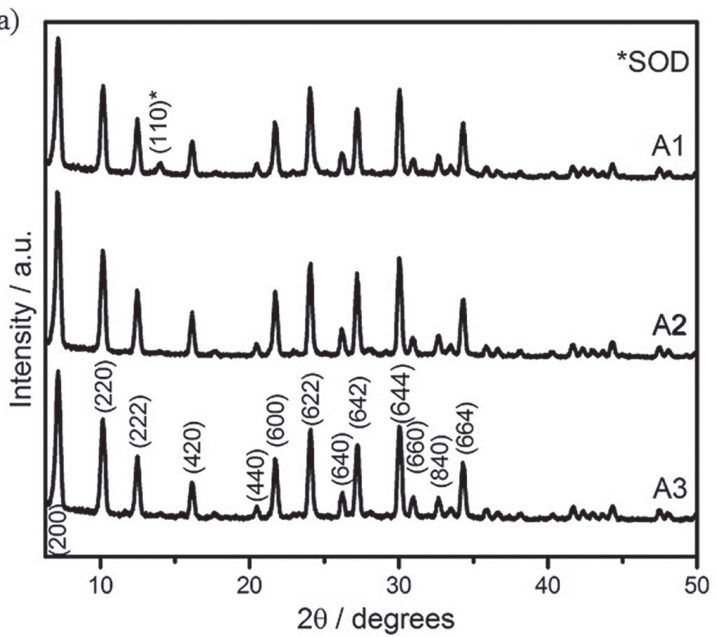

(b)

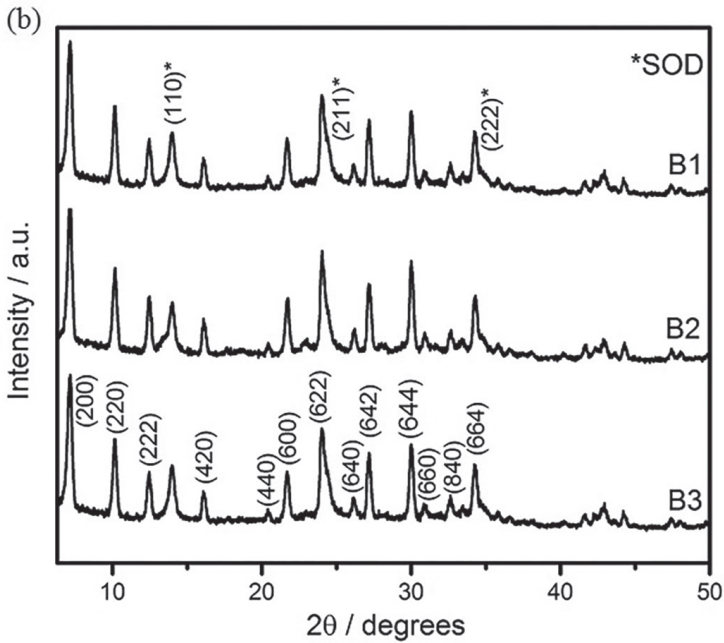

Figure 2. XRD patterns for procedures A and B and how they match the characteristic Linde Type A (LTA), hydrated zeolite and sodalite octahydrate $\left(^{*}\right.$ ) maxima; ${ }^{60}$ (a) samples A1, A2 and A3 with $0.5,1$ and 1.5 microwave-heating hours, respectively, and (b) samples B1, B2 and B3 with $0.5,1$ and 1.5 microwave-heating hours, respectively. 

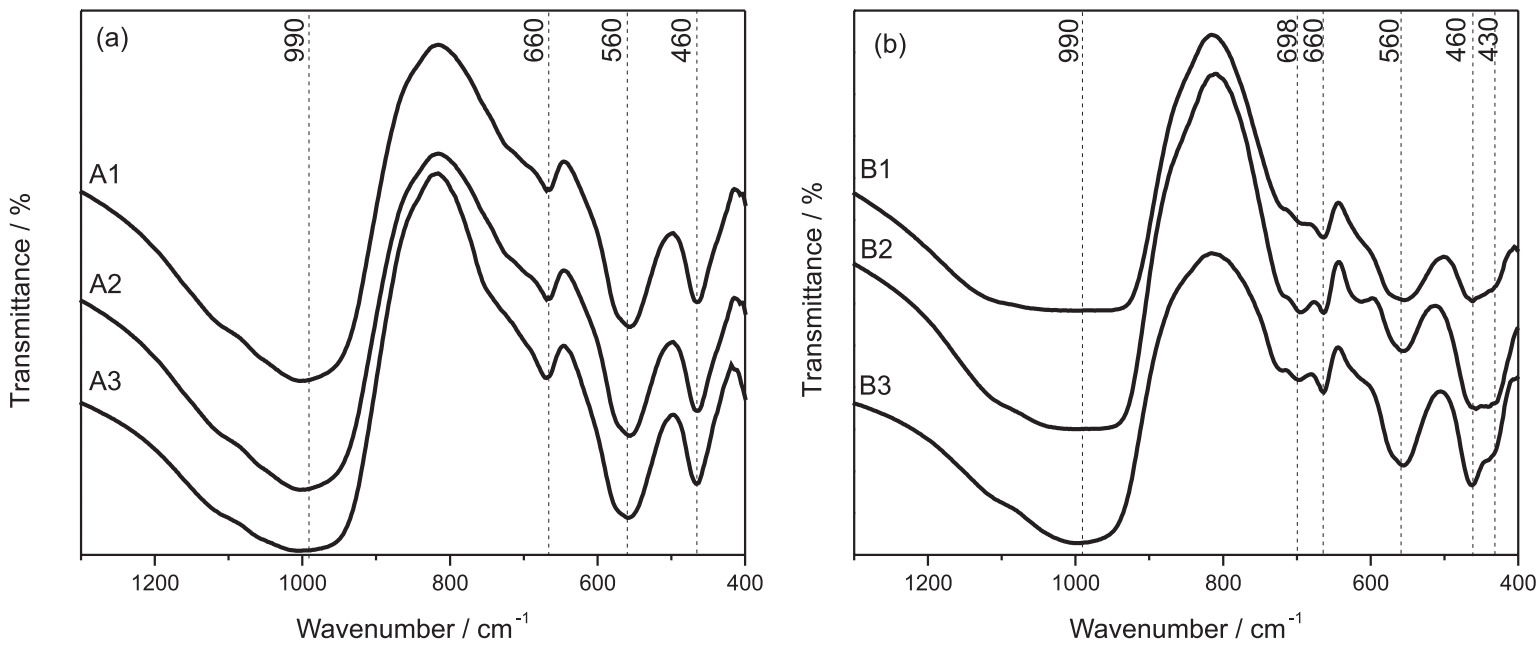

Figure 3. FTIR spectra of 4A zeolites obtained from (a) procedure A and (b) procedure B.
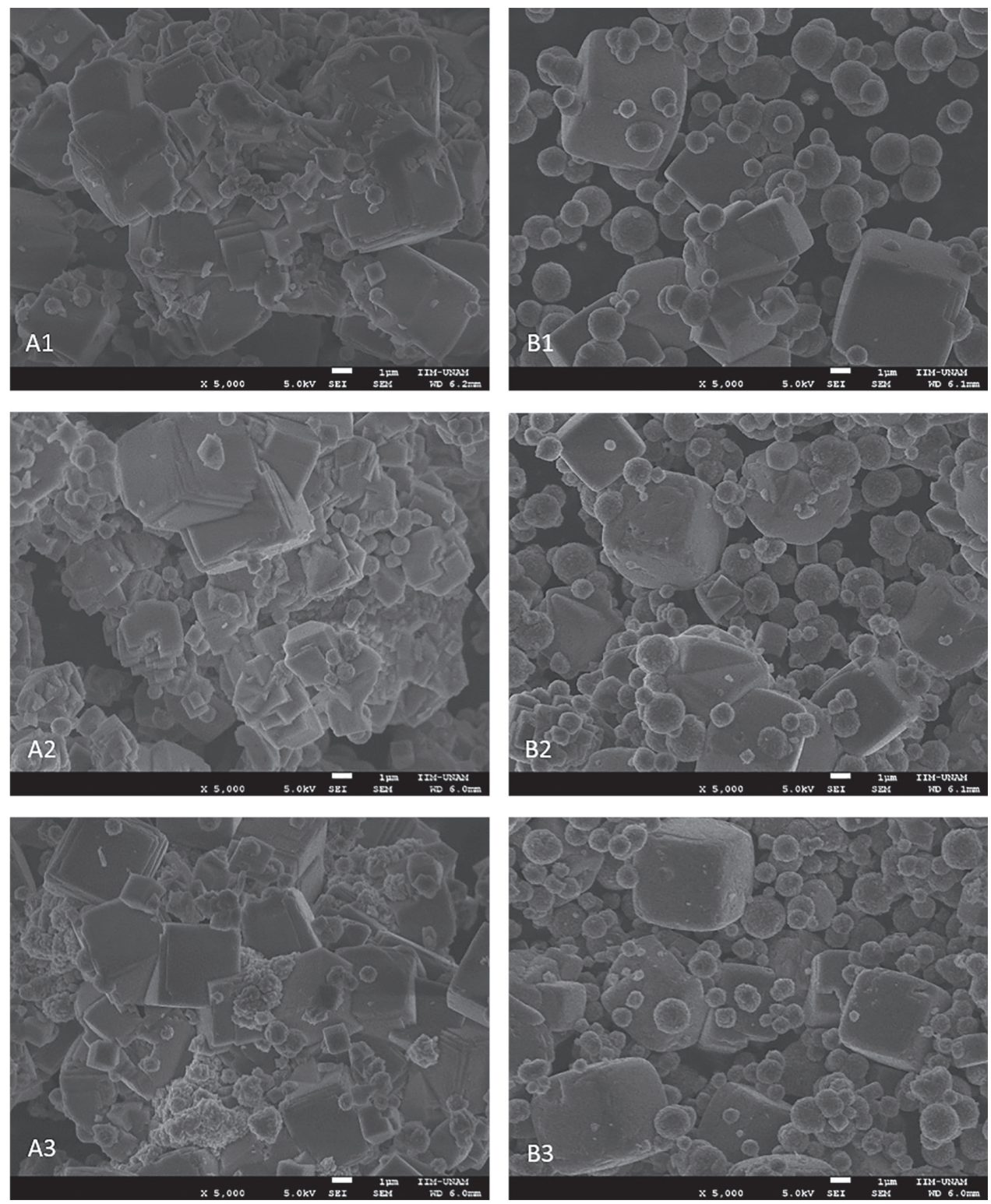

Figure 4. SEM images highlighting cubic shape of synthesized 4A zeolite. 
silica chains, making them more reactive, increasing the probability of nuclei creation. In the gel solution, nucleus growth commences as small, amorphous, spherical particles $^{52}$ that evolve into small crystals gathered together in hemispherical clusters. ${ }^{64}$ These clusters of small crystals feed on the nutritious solution until attaining their final size. When working with depolymerized RHA samples in this study, depolymerized silica initially facilitated the overpopulation of nuclei, which gradually led to the formation of small, spherical crystals. Some grew into well-defined cubic crystals until the concentration of the nutritious solution was no longer sufficient to feed them all, leaving several crystals underdeveloped, sodalite impurities according to XRD analysis.

According to Chal et al. ${ }^{65}$ and Gora et al.,${ }^{66}$ twin growth and intergrowth in the early agglomeration of nuclei can be explained. These nuclei feed on the gel solution and become cubic polycrystalline particles with a greater surface area per particle and, therefore, would be expected to assimilate material faster than single crystals with regular planar surfaces. ${ }^{66}$ At the same time, spherical morphologies of approximately $1 \mu \mathrm{m}$ (sodalite) and amorphous morphologies coexist alongside the cubic crystals. The zeolites in this study were synthesized with no need of seeding, template or matrix support.

Quantitative EDS analyses of both the crystals and the clusters gave similar composition, ca. $\mathrm{Na}_{1} \mathrm{Si}_{1} \mathrm{Al}_{1}$, showing that the clusters formed can be nuclei of LTA crystals or sodalite crystals (Figure 5). Similar results were observed in all the samples.

When zeolites are mixed with warm asphalt at over $100{ }^{\circ} \mathrm{C}$ in an asphalt mixture production process, the amount of water that is gradually released is proportional to the asphalt foaming effect. ${ }^{67}$ This was an important criterion that was considered in the present study for the combined use of zeolites as a warm mix asphalt additive (wmA) and silane as antistripping agent. The characterization of the samples obtained through TGA showed a clear difference between the water-releasing capacity of the A and B samples, observed at a maximum temperature of $130{ }^{\circ} \mathrm{C}$, the temperature that is normally used as a warm mix asphalt reference (Figure 6). In procedure $\mathrm{A}$, in which the crystallinity of $4 \mathrm{~A}$ zeolite is higher, the water-releasing capacity at a temperature of $130{ }^{\circ} \mathrm{C}$ was approximately $13.5 \mathrm{wt} \%$, while in procedure B, an average of 9.5 wt. $\%$ was reached. The loss of mass was registered at up to $380{ }^{\circ} \mathrm{C}$ due to the complete dehydration of the zeolites, which amounted to $19.11 \mathrm{wt} \%$ in procedure A and $14.35 \mathrm{wt} \%$ in procedure B. The highest water content was displayed by the sample with the greatest degree of crystallization. On
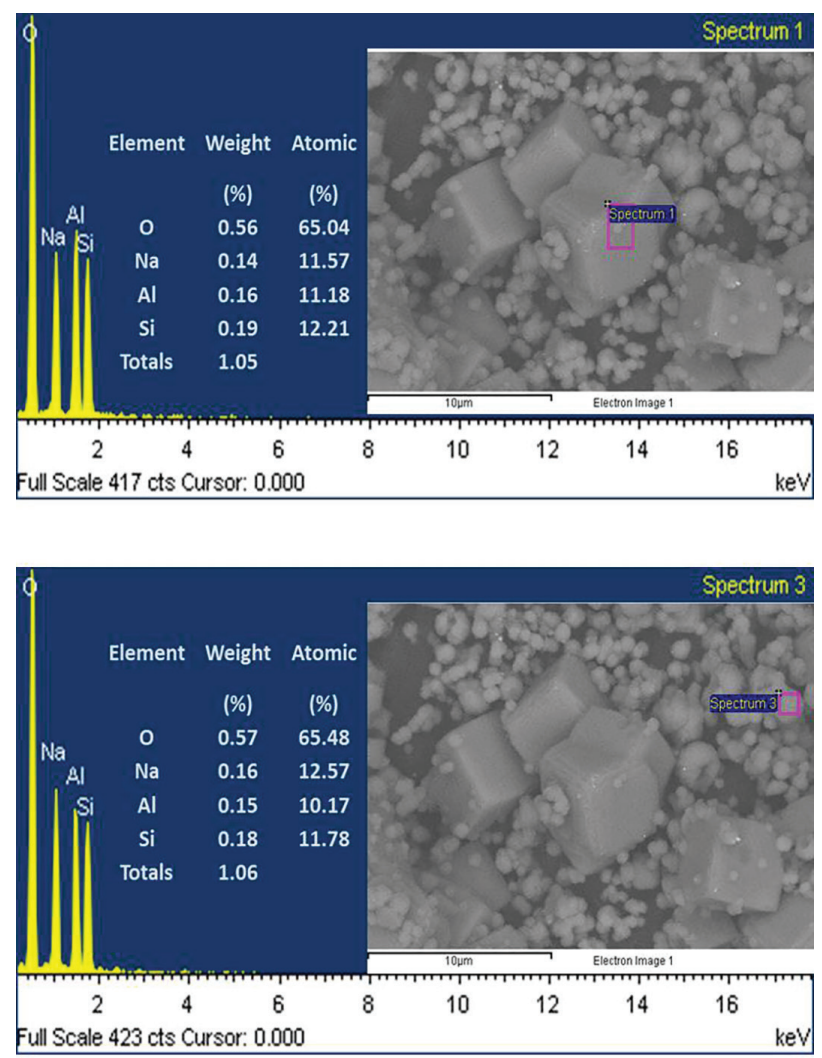

Figure 5. SEM/EDS analysis of the crystals and clusters of synthesized 4A zeolite obtained through procedure B sample 1 .

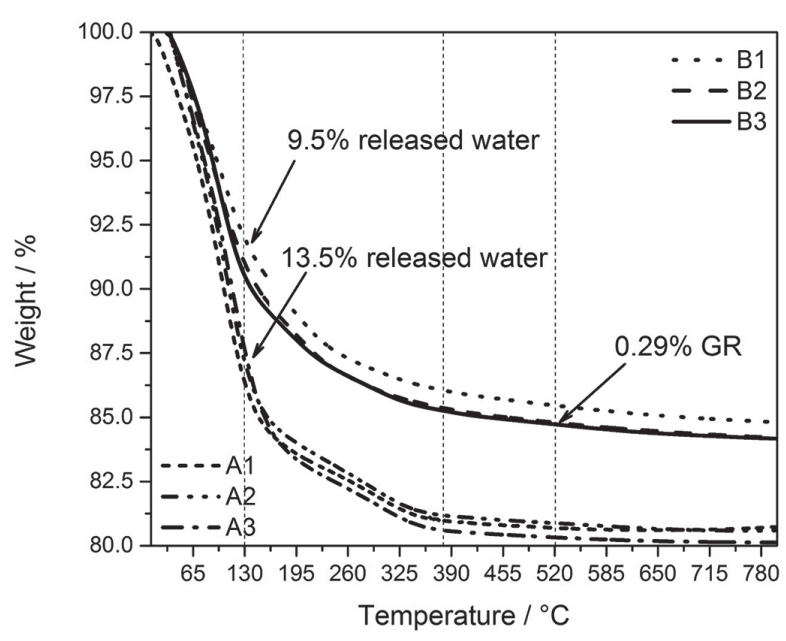

Figure 6. TGA curves of $4 \mathrm{~A}$ zeolites obtained from procedures A and B (GR: glycerol residues).

the other hand, there is a difference in the loss of mass of the samples between 380 and $520{ }^{\circ} \mathrm{C}$ corresponding to the oxidation of organic residues, in procedure $\mathrm{A}$ the loss belongs to $0.3 \mathrm{wt} \%$ and in procedure B to $0.59 \mathrm{wt} . \%$. The difference between both procedures corresponds to the glycerol residues due to depolymerization process used in procedure B and is equal to $0.29 \mathrm{wt} . \%$ 
Table 2. Effect of the silane content in the adhesion percentage of evaluated mixtures

\begin{tabular}{lccc}
\hline Mixture & Used additive & Concentration / wt. \% & Adhesion / \% \\
\hline M1 & additive-free asphalt mixture (blank sample) & - & 30 \\
M2 & sample A1 & 2.5 & 35 \\
M3 & sample A1 and commercial silane & 94 \\
M4 & commercial 4A zeolite and commercial silane $^{\mathrm{a}}$ & 2.5 zeolite/0.1 silane & 90 \\
M5 & commercial silane $^{\mathrm{a}}$ & 2.5 zeolite/0.1 silane & 85 \\
\hline
\end{tabular}

[3-(2-Aminoethylamino) propyl] trimethoxysilane; ${ }^{\mathrm{a}}$ Advera ${ }^{\circledR}$.

\section{Adhesion test}

The performance of the sample A1 as an additive was evaluated and compared to the performance of the commercial 4A zeolite and other additives described in Table 2.

At a warm mix asphalt temperature of approximately $130^{\circ} \mathrm{C}$, the adhesion percentage was meager in additive-free asphalt mixture (M1). The adhesion slightly increased when 4A zeolite sample A1 was added to mixture 2 (M2) due to the water-release foaming effect that boosts the superficial contact area of the asphalt and enhances aggregate coating. Since there is no known satisfactory adhesion performance between granite and asphalt, upon submitting the sample to stress, most of the asphalt was detached.

In mixture 3 (M3), the traditional option was applied, and would be to add both components separately at the same time at a recommended concentration of $2.5 \mathrm{wt} . \%$ synthesized $4 \mathrm{~A}$ zeolite and $0.1 \%$ silane. Therefore, the adhesion increased up to $94 \%$, reaching typical satisfactory adhesion performance levels slightly higher than that obtained with commercial zeolite (M4). The performance observed using silane by itself (M5) was not as high as the one obtained with the combined use of zeolite and silane. This was due to the absence of a wmA that would improve asphalt workability at warm mix asphalt temperatures, consequently lacking the required silane diffusion into the mixture needed to promote adhesion.

\section{Conclusions}

4A Zeolite was obtained from rice husk ash by applying a novel methodology. The ash was processed following two different procedures. In procedure $A$, the ash was used in a raw state, obtaining intergrown $4 \mathrm{~A}$ zeolites with a high crystallinity; whereas in procedure $\mathrm{B}$, the ash was subjected to a depolymerization reaction in anhydrous glycerol, obtaining 4A zeolite highly crystalline and well-defined cubic crystals and sodalite underdeveloped spherical crystals. The zeolites were crystallized at $100^{\circ} \mathrm{C}$ with microwave heating for $30 \mathrm{~min}$. It is important to note that neither procedure required the traditional aging time reported in previous studies, which highlights the short-time synthesis obtained by the methodology.

The synthesized 4A zeolite was utilized as a warm mix asphalt additive, showing a foaming and adhesion synergistic effect together with the silane, thereby increasing the adhesion capacity.

\section{Acknowledgments}

From the Instituto de Investigaciones en Materiales, we thank Adriana Tejeda Cruz for XRD analysis, Omar Novelo Peralta for SEM and Damaris Cabrero Palomino for TGA analysis. We also thank Patricia Girón García from Instituto de Geología for FRX analysis. All institutions belong to the Universidad Nacional Autónoma de México.

\section{References}

1. D’Angelo, J.; Harm, E.; Bartoszek, J.; Baumgardner, G.; Corrigan, M.; Cowsert, J.; Harman, T.; Jamshidi, M.; Jones, W.; Newcomb, D.; Prowell, B.; Sines, R.; Yeaton, B.; Warm-Mix Asphalt: European Practice; International Technology Scanning Program: USA, 2008.

2. Rubio, M. C.; Martínez, G.; Baena, L.; Moreno, F.; J. Cleaner Prod. 2012, 24, 76.

3. Vaitkus, A.; Čygas, D.; Laurinavičus, A.; Perveneckas, Z.; Balt. J. Road Bridge Eng. 2009, 4, 80.

4. Yin, H.; Investigation of Rheological Behavior of Asphalt Binder Modified by the Advera ${ }^{\circledR}$ Additive; Columbia University: New York, USA, 2009.

5. Zhang, J.; Effects of Warm-Mix Asphalt Additives on Asphalt Mixture Characteristics and Pavement Performance; University of Nebraska-Lincoln: Nebraska, USA, 2010.

6. Sanchez-Alonso, E.; Vega-Zamanillo, A.; Castro-Fresno, D.; Del Rio-Prat, M.; Constr. Build. Mater. 2011, 25, 2304.

7. Şengöz, B.; Topal, A.; Gorkem, C.; Road Mater. Pavement Des. 2013, 14, 933.

8. Topal, A.; Dokandari, P. A.; Mater. Res. 2013, 17, 1129. 
9. Vaiana, R.; Iuele, T.; Gallelli, V.; Tighe, S. L.; Can. J. Civ. Eng. 2014, 41, 183.

10. Nazzal, M. D.; Abu-Qtaish, L.; Kaya, S.; Powers, D.; J. Mater. Civ. Eng. 2015, 27, 1.

11. Ghabchi, R.; Singh, D.; Zaman, M.; Road Mater. Pavement Des. 2015, 16, 334.

12. Yang, L.; Tan, Y.; Adv. Eng. Forum 2012, 5, 299.

13. Topal, A.; Sengoz, B.; Vural, B.; Yilmaz, M.; Aghazadeh, P.; Oner, J.; Kaya, D.; Constr. Build. Mater. 2014, 57, 38.

14. Mizukami, F.; Porous Materials in Environmentally Friendly Processes, $1^{\text {st }}$ ed.; Elsevier Science B. V.: The Netherlands, 1999, p. 1-12.

15. Sengoz, B.; Topal, A.; Gorkem, C.; Constr. Build. Mater. 2013, 43, 242.

16. Kim, H.; Lee, S.-J.; Amirkhanian, S. N.; Constr. Build. Mater. 2011, 25, 183.

17. Diab, A.; You, Z.; Wang, H.; Soc. Behav. Sci. 2013, 96, 2858.

18. Sánchez-Alonso, E.; Vega-Zamanillo, A.; Calzada-Perez, M.A.; Castro-Fresno, D.; Constr. Build. Mater. 2013, 47, 240.

19. Vidal, R.; Moliner, E.; Martínez, G.; Rubio, M. C.; Resour. Conserv. Recycl. 2013, 74, 101.

20. Garcia-Cucalon, L.; Yin, F.; Martin, A.; Arámbula, E.; Estakhri, C.; Park, E. S.; J. Mater. Civ. Eng. 2016, $28,1$.

21. Schmidt, R.; Graf, P.; US pat. 4,036,661 1973.

22. Marzocchi, A.; Roberts, M. G.; Bolen, C. E.; US pat. 4,349,388 1980.

23. Gemayel, C. A.; Laboratory and Field Performance of Silane Anti-Strip Agent; Arizona Department of Transportation: USA, 1986.

24. Cui, S.; Blackman, B. R. K.; Kinloch, A. J.; Taylor, A. C.; Int. J. Adhes. Adhes. 2014, 54, 100.

25. Sherman, J. D.; Proc. Natl. Acad. Sci. U. S. A. 1999, 96, 3471.

26. Zhang, H.; Wang, F.; Yang, H.; Tan, Y.; Zhang, J.; Bu, X.; J. Am. Chem. Soc. 2011, 133, 11884.

27. Bonaccorsi, L.; Proverbio, E.; Microporous Mesoporous Mater. 2008, 112, 481.

28. Bonaccorsi, L.; Proverbio, E.; J. Cryst. Growth 2003, 247, 555.

29. Sathupunya, M.; Gulari, E.; Jamieson, A.; Microporous Mesoporous Mater. 2004, 69, 157.

30. Sathupunya, M.; Gulari, E.; Wongkasemjit, S.; J. Eur. Ceram. Soc. 2003, 23, 1293.

31. Shoumkova, A.; Stoyanova, V.; Fuel 2013, 103, 533.

32. Naser, S.; Maryam, A.; J. Mater. Sci. 2010, 45, 5692.

33. Shoumkova, A.; Stoyanova, V.; J. Porous Mater. 2013, $20,249$.

34. Tawatwachoom, T.; Khottoom, N.; Wairuangsiripon, S.; Rungrojchaipon, P.; Researchgate 2015, 1. DOI: 10.13140/ RG.2.1.2669.5847.

35. Pode, R.; Renewable Sustainable Energy Rev. 2016, 53, 1468.

36. Katsuki, H.; Komarneni, S.; J. Solid State Chem. 2009, 182, 1749.

37. Yusof, A.; Nizam, N.; Rashid, N.; J. Porous Mater. 2010, 17, 39.
38. Yap, W.; Tan, S.; Matsumoto, A.; Othman, R.; Yeoh, F.; Adsorption 2011, 17, 863.

39. Melo, C. R.; Francisco, A. C.; Kuhnen, N. C.; Rocha, M. R.; Melo, A. R.; Riella, H. G.; Angioletto, E.; Mater. Sci. Forum 2014, 799, 617.

40. Bohra, S.; Kundu, D.; Naskar, M.; Ceram. Int. 2014, 40, 1229.

41. Santasnachok, C.; Kurniawan, W.; Hinode, H.; J. Environ. Chem. Eng. 2015, 3, 2115.

42. Petkowic, D.; Rigo, T.; Radtke, C.; Pergher, S.; dos Santos, J.; Microporous Mesoporous Mater. 2008, 116, 548.

43. Cundy, C. S.; Collect. Czech. Chem. Commun. 1998, 63, 1699.

44. Herrmann, R.; Scharf, O.; Schwieger, W.; Studies in Surface Science and Catalyst, $1^{\text {st }}$ ed.; Elsevier B. V.: Germany, 2004.

45. Li, Y.; Chen, H.; Liu, J.; Yang, W.; J. Membr. Sci. 2006, 277, 230.

46. Li, Y.; Yang, W.; J. Membr. Sci. 2008, 316, 3.

47. Jawor, A.; Jeong, B. H.; Hoek, E. M.; J. Nanopart. Res. 2009 , 11,1795 .

48. Bogdal, D.; Microwave-Assisted Organic Chemistry One Hundred Reaction Procedures, $1^{\text {st }}$ ed.; Elsevier Ltd: London, UK, 2005.

49. Li, Y.; Liu, J.; Yang, W.; J. Membr. Sci. 2006, 281, 646.

50. Luengnaruemitchai, A.; Nimsuk, M.; Naknam, P.; Wongkasemjit, S.; Osuwan, S.; Int. J. Hydrogen Energy 2008, 33, 206.

51. Hu, Y.; Liu, C.; Zhang, Y.; Ren, N.; Tang, Y.; Microporous Mesoporous Mater. 2009, 119, 306.

52. Esmaeili, N.; Kazemian, H.; Bastani, D.; Iran J. Chem. Chem. Eng. 2011, 30, 1.

53. Behin, J.; Bukhari, S. S.; Dehnavi, V.; Kazemian, H.; Rohani, S.; Chem. Eng. Technol. 2014, 37, 1532.

54. Baig, M. A.; Patel, F.; Alhooshani, K.; Muraza, O.; Wang, E. N.; Laoui, T.; J. Cryst. Growth 2015, 432, 123.

55. Sharma, P.; Han, M. H.; Cho, C.; J. Nanomater. 2015, $2015,1$.

56. Zhu, G.; Li, Y.; Chen, H.; Liu, J.; Yang, W.; J. Mater. Sci. 2008, $43,3279$.

57. Alfaro, S.; Rodríguez, C.; Valenzuela, M. A.; Bosch, P.; Mater. Lett. 2007, 61, 4655.

58. Sánchez-Flores, N. A.; Pacheco-Malagón, G.; Pérez-Romo, P.; Armendáriz, H.; Valente, J. S.; Guzmán-Castillo, M. L.; Alcaraz, J.; Baños, L.; Blesa, J. M.; Fripiat, J. J.; J. Colloid Interface Sci. 2008, 323, 359.

59. Pacheco-Malagón, G.; Sánchez-Flores, N. A.; Blesa, J. M. S.; Baños, L.; Pérez-Romo, P.; Valente, J. S.; Guzmán-Castillo, M. L.; Hernández-Beltrán, F.; Fripiat, J.; Microporous Mesoporous Mater. 2007, 100, 70.

60. Mexican Norm M-MMP 4.04.009/03, http://normas.imt. $\mathrm{mx} /$ normativa/M-MMP-4-04-009-03.pdf, accessed in June 2017.

61. Treacy, M. M. J.; Higgins, J. B.; Collection of Simulated XRD Powder Patterns for Zeolites, $4^{\text {th }}$ ed.; Elsevier Science: Amsterdam, Netherlands, 2001. 
62. Valtchev, V. P.; Bozhilov, K. N.; J. Am. Chem. Soc. 2005, 127, 16171.

63. Socrates, G.; Infrared and Raman Characteristic Group Frequencies. Tables and Charts, $3^{\text {rd }}$ ed.; John Wiley \& Sons, LTD: London, UK, 2005.

64. Zah, J.; Krieg, H. M.; Breytenbach, J. C.; Microporous Mesoporous Mater. 2006, 93, 141.

65. Chal, R.; Gérardin, C.; Bulut, M.; van Donk, S.; ChemCatChem 2011, 3, 67.
66. Gora, L.; Streletzky, K.; Thompson, R.; Phillies, G.; Zeolites 1997, 18, 119.

67. Chimicz-Kowalska, A.; Bituminous Mixtures and Pavements IV, $1^{\text {st }}$ ed.; Taylor and Francis Group: UK, 2015.

Submitted: February 24, 2017

Published online: June 21, 2017 